\title{
UMA REFLEXÃO SOBRE AS CORRELAÇÕES ENTRE A LINGUAGEM E O CONHECIMENTO
}

\author{
Roberto Sarmento Lima (UFAL)
}

\section{Linguagem e história}

Num poema antológico, Oswald de Andrade expressou. com argúcia, a relação existente entre a linguagem e o modo de percepção (social) do mundo circundante, ou seja, a apreensão desse mundo pelo homem através de sua capacidade de linguagem:

Dê-me un cigarro

Diz a gramática

Do professor e do aluno

E do mulato sabido

Mas o bom negro e o bom branco

Da Nação Brasileira

Dizem todos os dias

Deixa disso camarada

Me dá um cigarro

O que o poeta tematiza é a constatação de que, no processo do conhecimento, interagem lingua e condiçáo histórico-social do indivíduo, de modo que a expressão lingüística não pode ser tida como mero revestimento de uma idéia ou de um sentimento, mas é constitutiva do próprio conhecimento (intelectual-afetivo) da realidade. Assim é que a formalização (e, por isso. o artificialismo) do conhecimento - representada no poema pela "gramática do professor e do aluno e do mulato sabido" - não significa exatamente a vivência real do individuo em sua rede de relações intersubjetivas. O que, de fato, determina sua visão de mundo é a prática cotidiana, sua aderência a uma situação histórica específica, seu fazer em contato com outros individuos - enfim. o mundo da objetividade. Entretanto. seria simplismo afirmar que, nessa relação, a consciência é apenas um rceptáculo passivo do mundo exterior, como, por exemplo, um espelho reflete una paisagem. (Como entender isso"? 
Marx, na sua primeira tese a respeito de Feuerbach, denuncia o estado de precariedade do materialismo desenvolvido até ali, o qual se satisfaz em tomar o concreto, a efetividade e o sensível apenas sob a forma de objeto, algo típico da teoria do reflexo mais mecanicista, em cujo entender o conhecimento é reduzido à captação passiva da exterioridade. O que Marx defende - inaugurando um novo momento na teoria do conhecimento materialista - é que entre sujeito e objeto se dá uma verdadeira interação, a fim de apagar as fronteiras, até então vistas como rígidas e intransponíveis, de ambas as esferas. O objeto não só é captado pelo sujeito, mas este, num movimento rumo ao objeto, transforma-o a partir de sua prática, isto é, de sua intervenção no mundo das coisas, da subjetivação da coisidade posta. Esse lado ativo do sujeito, que o materialismo mecanicista ignora e que o idealismo por definição valoriza, era o componente que faltava e que, desde Marx, iria preencher esse vazio, introduzindo-se, assim, no processo do conhecimento, o conceito de práxis.

E o que significa esse lado ativo do sujeito, esse fator subjetivo no momento da captação da coisa, tornada, então, objeto? Práxis não pode ser entendida - sob pena de se cair em novo reducionismo - como atividade material do homem tout cout ; práxis é, antes, essa atividade material mediada pela consciência, que nunca é exclusivamente individual, mas social e compartilhada no interior da cultura. É preciso, pois, não reduzir a práxis - conceito nuclear da teoria marxista - a um praticismo vulgar, vazio de subjetividade, já que práxis é a ação humana cuja especificidade se resolve na passagem do objetivo para o subjetivo e vice-versa. É ação humana finalista, relacional e consciente, através da qual o sujeito, ao tempo em que produz objetos com coisas do mundo, também se autoproduz.

A consideração do lado ativo da filosofia da práxis abriga, portanto, além do movimento da mão, o movimento da consciência, pois entre o gesto e o pensamento não pode haver clivagem, sendo qualquer tentativa de separação um artifício desenvolvido pelas teorias dualistas, o que contraria o caráter eminentemente monista do marxismo. Esse lado ativo do sujeito, na transformação da coisidade do mundo em objetos sociais, é o pensamento, intimamente identificado com o lugar social de quem produz: a subjetividade, a consciência. 
Mas não existe pensamento ou consciência sem linguagem. Por isso é que, voltando ao poema de Oswald de Andrade, "o bom negro e o bom branco / Da Nação Brasileira / Dizem todos os dias / Deixa disso camarada / Me dá um cigarro". A subjetividade do indivíduo, traduzida na sua fala, é um modo de interferir na realidade, pois pela interação verbal os comportamentos podem sofrer mudanças, da mesma forma que certa situação pode influenciar e alterar os conteúdos de uma fala. Sujeito e objeto não são categorias isoladas, mas implicam-se mutuamente; igualmente, linguagem, entendida como suporte da consciência, e realidade social objetiva constituem faces de um mesmo problema - o que contraria as teses de que a língua é inata e que a aquisição da linguagem se dá em abstrato, fora das condições materiais de produção. A língua em abstrato é a "gramática do professor", que impõe uma locução artificiosa, à revelia da consciência social é da inserção do indivíduo na cultura. Por isso, essa língua é, nos casos de realização discursiva vis-à-vis, inoperante, não se realiza na confluência do acontecer social efetivo.

Pelo que o poema de Oswald deixou sugerido, o discurso, a prática lingüística e não a língua abstrata, não se divorcia em momento algum da prática cotidiana do homem e de sua história em condições reais. O homem - dotado de consciência e de linguagem age no mundo e sobre o mundo em sua concretude. Não há idéias isoladas da efetividade; não há consciência pura, mas toda manifestação da consciência só se realiza através da linguagem. Se se entende que a linguagem é um sistema em que as significações só se dão em uma forma, seu suporte material - todo signo une um significante (parte sensivel e material do signo) a um significado (sua parte conceptual), dirià Saussure -, entende-se, igualmente, que o pensamento, para se concretizar, necessita da palavra ou de qualquer outro suporte semiológico, como o gesto, o desenho, a imagem etc. Pois "fora de sua objetivação, de sua realização num material determinado (o gesto, a palavra, o grito), a consciência é uma ficção"1. Nesse sentido, a mera reprodução de uma unidade fonológica, sem que se dê conta do significado que ela comporta, não constitui ato discursivo ou de linguagem. Schaff ${ }^{2}$ ilustra isso com o exemplo do

BAKHTIN, M. Marxismo e filosofia da linguagem: problemas fundamentais do método sociológico na ciência da linguagem. 1981, p. 117-118.

SCHAFF, A. Linguagem e conhecimento, 1974. 
papagaio, que - por desconhecer o conteúdo nocional das palavras que repete - não pode ser considerado um ser da fala.

\section{Linguagem e pensamento}

O pensamento é, por isso, pensamento verbal, já que "não é possível o pensamento sem linguagem"3. Entretanto, pensamento não $e ́$ linguagem: ambos formam uma unidade, de modo que, nessa relação de interdependência, um não subsiste sem o outro. O pensamento e a linguagem, juntos, são a garantia de que se está dando o processo do conhecimento, pois a consciência - diz Marx - é tão antiga quanto a linguagem:

[...] verificamos que o homem tem também "consciência". Mas, ainda assim, não se trata de consciência "pura". Desde o início pesa sobre o "espírito" a maldição de estar "contaminado" pela matéria, que se apresenta sob a forma de camadas de ar em movimento, de sons, em suma, de linguagem. A linguagem é tão antiga quanto a consciência - a linguagem é a consciência real, prática, que existe para os outros homens e, portanto, existe também para si mesmo; e a linguagem nasce, como a consciência, da necessidade de intercâmbio com outros homens ${ }^{4}$.

A parte final desse fragmento é lapidar: Marx e Engels situam a gênese do conhecimento (consciência e linguagem) no interior da produção material, instância em que os homens, modificando a natureza e a si próprios, necessitam não só do intercâmbio que o trabalho coletivo impôs como também, ao mesmo tempo, do intercâmbio lingüístico que medeia a atividade do trabalho. É essa passagem de Marx a que melhor, a nosso ver, traduz a primeira tese sobre o materialismo desenvolvido até Feuerbach no tocante à participação do lado ativo, subjetivo, na prática social. Esse lado ativo é a atuação da linguagem, reclamada, exigida pela necessidade de comunicação (mas não só por isso) entre os homens no momento do trabalho.

A linguagem, porém, não nasceu apenas em virtude dessa necessidade de comunicação entre os homens na instância do trabalho; a linguagem é, acima de tudo, constitutiva do processo de humanização

SCHAFF, op. cit., p. 189.

MARX, K. \& ENGELS, F. A ideologia alemã: I - Feuerbach. 1984, p. 43; grifos nossos. 
a partir do que só então é possível falar de conhecimento: "o homem [foi] tornando-se homem juntamente com o trabalho e a linguagem, de modo que nem o homem, por seu lado, nem o trabalho ou a linguagem, por sua vez, vieram primeiro" ${ }^{\text {. }}$. Como o gesto e o pensamento (insistimos: o pensamento é mediado pela linguagem) não se separam a não ser artificialmente, dentro de uma percepção fetichizada da realidade -, a fabricação de instrumentos de trabalho é paralela à gênese da linguagem. Gordon Childe ${ }^{6}$, distinguindo instrumentos "ocasionais" de instrumentos "padronizados", afirma que o homem - no primeiro momento de criação de instrumentos, deles servindo-se repetitivamente a ponto de padronizar-lhes o uso (isto é, destina-los a uma função específica) - foi capaz de alsistrair o gênero (o modelo) e, só então, de distinguir o objeto-matriz, singular, de seus similares derivados, que constituem, nessa relação de semelhança para com o modelo, as manifestações concretas correspondentes ao conceito original. Assim, "a primeira abstração, a primeira forma conceptual, foi fornecida pelos próprios instrumentos"7. E conceito é, definitivamente, linguagem, conhecimento.

\section{Linguagem e trabalho}

Conceito, consciência, linguagem, conhecimento, tudo isso se dá no interior de um mesmo processo: no âmbito do trabalho, no intercâmbio entre os homens. Marx insiste, aqui e ali, em que a formação da consciência (leia-se: conhecimento) do homem não pode realizar-se a não ser por esse intercâmbio:

De certa forma, sucede ao homem como à mercadoria. Pois ele não vem ao mundo nem com um espelho, nem como um filósofo fichtiano: eu sou eu, o homem se espelha primeiro em outro homem. Só por meio da relação com o homem Paulo, como seu semelhante, reconhece-se o homem Pedro a si mesmo como homem. Com isso vale para ele também o Paulo, com pele e cabelos, em sua corporalidade paulinica, como forma de manifestação do gênero humano ${ }^{8}$.

FISCHER, E. A necessidade da arte. 1983, p. 34.

Apud FISCHER, ibidem.

Ibidem, p. 37.

MARX, K. O capital: crítica da economia política. 1985 , v. I, p. 57; grifos nossos. 
O processo do conhecimento não é, pois, uma ocorrência unilateral; ao contrário, faz-se na intersubjetividade, na interaçcio entre os homens, na relação que se estabelece entre eles - relação não só econômica (já que Marx colocou essa relação em pé de igualdade com o mundo das mercadorias), mas também lingiüistica (o que apenas está implícito nesse fragmento, pois a corporalidade do homem não é traduzida como essência eterna e imutável, mas em termos definidamente históricos: a corporalidade nomeada paulínica - a particularidade - integra, assim, num movimento dialético, o gênero humano, a generalidade).

Desse modo, vê-se que, para Marx, o conhecimento não é uma categoria abstrata, intemporal e descontextualizada, não é uma atividade exclusiva do espírito, mas uma categoria ontológico-social: o conhecimento - respeitando-se sua etimologia, conhecimento - dáse no âmbito das relações sociais, da práxis, do trabalho e, assim, evolui historicamente. O conhecimento não é, pois, algo dado, mas construido pela e na objetividade da práxis, intermediado pela linguagem.

Atento a essa perspectiva, Paulo Freire problematizou certa vez a ligação necessária entre o conhecimento e a linguagem. Referindo-se ao objeto como um dado exterior e, depois, à sua subjetivação, o educador apontou, dentro do raciocínio que estamos aqui defendendo, as relações homem-mundo como homólogas às relações conhecimento-linguagem:

[...] admitindo-se que todos os seres humanos morressem, mas ficassem as árvores, os pássaros, os animais, os mares, os rios, a Cordilheira dos Andes, seria isto mundo? "Não!", respondeu decidido [um camponês chileno com quem Freire conversava]: "Faltaria quem dissesse: isto è mundo"9

Embora Marx não negue a existência de uma natureza à margem da práxis, anterior à história, o conhecimento dessa natureza, porém, só se dá na e através da práxis, instância na qual o homem, operando sobre o meio, dá finalidade ao conhecimento. A relação entre a palavra e a coisa (como, no exemplo dado por Freire, entre a palavra mundo e a coisa mundo) eleva a coisa-em-si à sua condição de objeto, após ou durante a sua apropriação pelo sujeito. Para

9 FREIRE, P. Ação cultural para a liberdade e outros ensaios. 1982, p. 23; grifo nosso. 
elucidar melhor essa questão tão sutil, Marx propôs dois termos, na língua alemã, para designar a palavra objeto - Objekt e Gegenstand -, sendo este o objeto humanizado, a subjetividade que o trabalho incorporou ao produto, e aquele, o objeto-em-si, realidade exterior e ainda não transformada pelo trabalho. (Caetano Veloso: "Está provado que só é possivel / filosofar em alemão”.)

A coisa-em-si mundo transformou-se, pela linguagem, pela subjetividade, no objeto-mundo; transformou-se, porém, não por meio de um ato mágico de nomeação simplesmente, mas porque o ato lingüistico é concomitante, como já vimos, com o ato de produzir materialmente. $O$ ato lingüistico, discursivo, medeia a atividade prática do homem, colocando-se entre o sujeito que produz (ou graças ao sujeito que produz) e o objeto que é produzido. $O$ ato lingüístico é classificatório, judicativo, interpretativo, dá sentido às coisas humanizadas. Por isso é que o conhecimento, assim definido, não é mera intuição, pois "intuição é aquilo que não tem a mediação discursiva. Distingue-se, portanto, do conhecimento mediado que subentende a interposição, entre objeto e sujeito, de um elemento mediador, que é o discurso"

\section{Linguagem: figuratividade e abstração}

Cabe ressaltar, no entanto, que, quando falamos de linguagem, não a estamos entendendo no sentido restrito de linguagem verbal; esta refere-se apenas ao auge do processo de representação e amadurecimento do ato de pensar. Mas há outros meios de semiologização, como a nãoverbal: a linguagem gestual, a pictórica, a musical, por exemplo. Até, nos tempos primitivos, a representação do pensamento e as formas de conhecimento, de acesso à inteligência do mundo, davam-se através da pintura. Os homens dos períodos paleolítico e neolítico, que ainda não dominavam a fala como hoje a entendemos, comunicavam-se por intermédio de desenhos e representações pictóricas gravadas no interior das grutas. Interessante frisar que essa linguagem não se deu uniformemente nos dois períodos apontados: o homem do paleolítico, ainda nômade, desconhecia a agricultura e, por isso, não se prendia à terra; mal dominava os mecanismos de defesa pessoal; a necessidade de

10 Chasin, J. A questão ontológica. s. d. (mimeografado), p. 130; grifos nossos. 
viver em grupo era bem maior, portanto. Já o homem do neolítico, ao contrário, pastoreava e arava a terra, cozia seus alimentos, ensaiava uma divisão natural do trabalho - forma ancestral, segundo Marx, da divisão social do trabalho -, pela qual o homem passou a submeter a mulher. Assim eram distribuídas e classificadas as atividades do homem (basicamente caça e pesca) e as da mulher (agricultura e culinária). Não é à-toa que, posteriormente, a imagem da mulher, na mitologia e na literatura, tenha sido fundida à imagem da terra - ambas vistas como fontes de fecundidade. No período paleolítico, quando era maior o grau de incerteza e de medo perante os perigos e as ameaças postas pela natureza e, por isso, menor a capacidade de abstração do homem - já que o incipiente desenvolvimento das forças produtivas o impedia de retirar seu pensamento dentre as coisas chãs do cotidiano -, a representação pictórica nas cavernas ilustrava, com o máximo de fidelidade ao real, cenas da vida comunitária, lutas contra animais etc. A arte figurativa funcionava como uma extensão da realidade e tinha por fim comunicar, informar, avisar (algo parecido com a modalidade performativa da linguagem, segundo Austin). Não era nesse contexto ainda conhecida a chamada função estética da arte, pelo menos liberta de sua ligação com o reino da necessidade, dado o caráter extremamente utilitário da pintura e do desenho. No período neolítico, o homem dominava melhormente a natureza; por isso, a arte, com o avanço das forças produtivas, permitia-se ser mais simbólica que figurativa, mais esquemática que pictórica, mais estética e menos utilitária. As imagens eram, antes, abstrações da realidade que a expressão fiel da mesma realidade, em virtude do maior domínio técnico do homem sobre o mundo da produção.

A linguagem - seja ela verbal, seja não-verbal - sempre se interpôs, sempre se colocou como mediação necessária entre o sujeito e o objeto do conhecimento. Este é o lado ativo do sujeito que não tinha sido compreendido pelo materialismo até Feuerbach. Que a linguagem exprime o mundo social já percebemos. Como, então, entender a concepção de que a linguagem, refletida a realidade, pode exercer sua influência sobre essa mesma realidade? A palavra tem função social: a gênese da linguagem está diretamente associada à gênese do homem como produtor, como ser do trabalho. O trabalho, insistimos, além de representar uma ação que conduz o ser natural a uma condição superior (a Aufhebung hegeliana), negando-o e transformando-o, é permeado por um momento ideativo, consciente, que consiste na apropriação subjetiva das coisas do mundo. O trabalho não é, pois, uma ação exterior 
separada da subjetividade do homem que trabalha; essa separação, aliás, ocorre no que Karel Kosík chama de "práxis fetichizada" ou mundo da "pseudoconcreticidade" ", sugerindo-se que o objeto de algum modo se torna independente do sujeito. Decorrente dessa visão é a idéia dicotômica de verdade ("práxis humana") e não-verdade ("pseudoconcreticidade"), no âmbito mesmo do marxismo, terminando por dar foros de autenticidade àquilo que a própria metodologia desse corrente de pensamento tenta superar, que é a dissolução da unidade sujeitoobjeto $^{12}$. Seja como for, por mais mecânica a ação humana que intervém na realidade, no momento em que trabalha, o homem pensa; e esse pensamento é inseparável de sua formalização semiológica (verbal ou não-verbal), de modo a não se compreender o trabalho sem sua recorrência à ação, à linguagem e ao conhecimento.

O pensamento, para ser digno desse nome, é, enfim, necessariamente semiológico, representacional, simbólico, porque, sem a carnadura semiológica, não há pensamento ${ }^{13}$. Outro "erro" fundamental ${ }^{14}$ - além da separação entre teoria e prática - é separar forma e conterido. Pois o que é o pensamento senão forma e conteúdo

1 OSiK, K. Dialética do concreto, 1976. Diz esse autor: "A pseudoconcreticidade é justamente a existência autônoma dos produtos do homem e a redução do homem ao nível da praxis utilitária" (p. 19).

12 Isso só prova que não há método de análise que esteja completamente a salvo de suas aporias.

13 Foi desejo entre os russos futuristas, no início do século XX, criar uma "poesia transracional", isto é, dotada de significante, no dizer saussuriano, mas independente de um conteúdo lógico e interpretativo - sonho que vem assaltando a literatura desde os simbolistas franceses. Ora, mesmo o silêncio, em poesia ou não, é passivel de interpretação.

14 Temos aqui certo pudor em admitir a existência do erro em caráter metodológico, porque tal atitude implica reconhecer que há uma verdade indiscutivel. E, em ciência e em filosofia, parece-nos que reconhecer para todo o sempre o estatuto categórico da verdade atenta contra a própria noção moderna de verdade, que, desde Nietzsche, pelo menos, se relativiza. Esse filósofo, aliás, alimentou certa versão da verdade como utilidade, cara às filosofias da ação e do pragmatismo, ao afirmar em primeira mão que o "verdadeiro não significa em geral senão o que é apto à conservação da humanidade", o que serviria para justificar, por exemplo, ações políticas conservadoras e dominadoras em nome do chamado "bem universal", outro conceito sujeito a revisão e discussão. (A esse respeito cf. ABBAGNANO, N. Dicionário de filosofica. 1982, p. 961.) 
juntos? Pode-se, aliás, pensar no vazio, sem o suporte da linguagem? Pode-se pensar à revelia de uma forma que dê consistência e concretude ao pensamento? Pode-se pensar sem a interferência de uma língua e, correlativamente, de um ponto de vista cultural pelo qual se interpretam o mundo e a vida? Responder afirmativamente a essas questões corresponde a admitir que é possível haver dança sem dançarino, ou abstrato sem concreto.

\section{Educação dos sentidos}

É justamente na confluência dessa problemática - a da impossibilidade de separar ação e pensamento - que se coloca este novo problema, não menos importante: a inseparabilidade entre linguagem e conhecimento. Linguagem é, já frisamos, a capacidade de semiologização, que se resolve através de diferentes canais: os sentidos e a palavra. Não se pode prescindir, no processo do conhecimento, da atividade do sujeito que conhece. O sujeito não é tabula rasa na qual se inscrevem os dados do real. O sujeito, na apreensão do real, co-participa, co-labora, co-nhece. Para isso, servese, ao mesmo tempo, de sua mente e de seus sentidos. Os cinco sentidos captam o objeto, atribuindo-lhe uma interpretação que está ausente no animal. A leitura que os sentidos humanos fazem do mundo é carregada de significados sociais. O olhar humano é, assim, mais do que um simples olhar; é uma atribuição de significações.

Essa visão antropológica dos sentidos já se encontra no jovem Marx dos Manuscritos econômico-filosóficos, de 1844, onde trata, ainda que indiretamente, da inter-relação entre conhecimento e linguagem, acusando que o ato de conhecer só é possível quando o homem, superado seu estado bruto, for capaz de educar a linguagem dos sentidos:

É evidente que o olho humano goza de modo distinto que o olho bruto, não humano, que o ouvido humano goza de maneira distinta que o bruto etc.

Como vimos, o homem só não se perde em seu objeto quando este se configurar como objeto humano ou homem objetivado ${ }^{15}$.

15 MARX, K. Manuscritos econômico-filosóficos e outros textos escolhiclos. 1987, p. 177; os grifos são de Marx. 
Pelo que se lê em Marx nota-se que só ocorre o conhecimento quando os pólos opostos sujeito e objeto transitarem um para o outro, ou seja, quando o objeto se tornar humano e o homem puder, assim. objetivar-se, já que a relação não é unilateral, mas dialética. Dá-se, pois, o conhecimento quando o canal de acesso à realidade sofrer o mesmo processo de humanização. Esse canal - ou os sentidos ou a palavra, ou ambos - constitui o canal especificamente humano e fïlogeneticamente maduro para mediar o conhecimento.

Os sentidos, já humanizados, são os sentidos que já ultrapassaram a condição primeira de sua aderência à natureza: são, portanto, os sentidos que, num aprendizado cultural, são capazes de apreender os objetos, atribuindo-lhes significações. que são históricas e sociais, nunca meramente individuais ${ }^{16}$. Esse captar objetos e esse dar-lhes significados referem-se ao lado ativo do conhecimento, o fator subjetivo que o materialismo mecanicista desconhece. $\mathrm{O}$ conhecimento é, pois, a resultante desse pensar com os sentidos, como observou Marx: "Por isso o homem se afirma no mundo objetivo não apenas no pensar, mas também com todos os sentidos"17.

O conhecimento se trava por meio de uma semiologização que, de início, é sensorial, mas que já é linguagem - isso tanto no plano filogenético como no ontogenético. Comparemos, então, o desenvolvimento de uma criança com o da própria humanidade. Sendo a linguagem o canal por que se dá o conhecimento, pressupõe-se que a linguagem não seja um mero artefato, coisa entre coisas, mas um produto social - portanto, elaborado, não-natural -, um produto cujo modo de ser implica a interação entre sujeito e objeto.

O homem não apenas vê ou ouve, mas, em sua vida social. aprende a ver, a sentir, a ouvir,

16. A percepção da realidade, como estamos observando nesta discussão, em nome de uma ontologia social que preside à constituição das relações homem-mundo e, necessariamente, homem-linguagem, põe por terra a noção de que existiria, como se acreditou durante a vigência do estilo romântico, no século XIX, uma arte essencialmente individualista e intimista, considerada assim em detrimento da participação da objetividade no âmbito mesmo da interaçào humana ou, pelo menos, em prejuizo do diálogo entre sujeito e objeto, no qual este se elidiria, ou se esvaneceria, em função daquele.

17 MARX, K. Manuscritos, p. 178; grifo de Marx. 


\begin{abstract}
e o resultado do seu esforço, mesmo antes de iniciar-se esse processo, já está assinalado - como uma tarefa a realizar sobretudo na forma de linguagem humana, da universalidade da consciência humana tal como se fixou na linguagem. Para inserir-se na vida da sociedade, o homem deve dar uma articulação estável aos fenômenos, de acordo com a própria estrutura que é dada - de um modo inteiramente independente do homem - na linguagem, isto é, na consciência social materializada $^{18}$.
\end{abstract}

A percepção sensorial dos animais, ao contrário, não sofre nenhuma elaboração: seu objeto e seu modo de captar o objeto são imediatos, não passam por mediações. Por isso, "conhecer", no que toca diretamente aos animais, é um termo que se deve colocar sempre entre aspas. Já o homem mediatiza sua relação com a natureza através da unidade indissolúvel pensamento-linguagem, com que dá finalidade a seus atos, além de acrescentar-lhes novos significados. Um bom exemplo disso, na literatura, é o momento em que Bentinho, personagem-narrador de Dom Casmurro, de Machado de Assis, cria, para designar o misterioso encanto de Capitu, a metáfora dos "olhos de ressaca", passagem que vale a pena transcrever:

Olhos de ressaca? Vá, de ressaca. É o que me dá idéia daquela feição nova. Traziam não sei que fluido misterioso e enérgico, uma força que arrastava para dentro, como a vaga que se retira da praia, nos dias de ressaca.

Ao forjar a expressão metafórica, Bentinho une objeto natural e objeto humano através do conhecimento que ele tinha do ser natural "mar", conhecimento, por sua vez, já carregado de significados sociais. A metáfora, assim como, de resto, a linguagem socialmente compartilhada, remete a um conhecimento de mundo que é falado. comentado, avaliado. E jamais o indivíduo Bentinho teria criado a metáfora que criou se não vivesse em um contexto marcado por injunções da cultura em que vivia - contexto, diríamos, não especificamente brasileiro, mas ocidental, no mínimo.

Marx, nos Manuscritos, esclarece que, se os sentidos não sofressem essa elaboração de que já falamos - a sua humanização --, o homem não poderia com-preender a realidade como objeto, mas apenas como coisa:

18 MÁRKUS, G. A teoria do conhecimento no jovem Marx. 1974, p. 60; grifo nosso. 
A formação dos cinco sentidos é um trabalho de toda a história universal até nossos dias. O sentido que é prisioneiro da grosseira necessidade prática tem apenas um sentido limitado. Para o homem que morre de fome não existe a forma humana da comida, mas apenas o seu modo de existência abstrato de comida $[\ldots]^{19}$

Assim, a linguagem, na mesma proporção em que sofre a influência do meio social, age sobre o meio, porque, através dela, a realidade é cumulativamente atravessada por novas significações: é esse, enfim, o fazer cultural, sempre dinâmico e contínuo. O julgamento da realidade, que é próprio do conhecimento, concerne, antes, à linguagem e ao ato de nomeação, pelo qual as coisas atingindo a dimensão de objeto - são classificadas, definidas, pensadas. Linguagem, que nunca pode ser tomada em abstrato, mas em intima correlação com a materialidade da prática social.

\section{REFERÊNCIAS BIBLIOGRÁFICAS}

ABBagnano, Nicola. Dicionário de filosofia. 2. ed. São Paulo: Mestre Jou, 1982.

BAKHTIN, Mikhail. Marxismo e filosofia da linguagem: problemas fundamentais do método sociológico na ciência da linguagem. 2. ed. São Paulo: Hucitec, 1981.

CHASIN, José. A questão ontológica. s. d. (mimeografado).

FIORIN, José Luiz. Linguagem e ideologia. São Paulo: Ática, 1988.

IISCHER, Ernst. A necessidade da arte. 9. ed. Rio de Janeiro: Zahar, 1983.

FREIRE, Paulo. Ação cultural para a liberdade e outros ensaios. 7. ed. Rio de Janeiro: Paz e Terra, 1982.

KOSÍK, Karel. Dialética do concreto. 2. ed. Rio de Janeiro: Paz e Terra, 1976.

19 MARX, K. Manuscritos, p. 178; grifos de Marx. 
MÁRKUS, György. A teoria do conhecimento no jovem Marx. Rio de Janeiro: Paz e Terra, 1974.

MARX, Karl. O capital: crítica da economia política. 2. ed. São Paulo: Nova Cultural, 1985, v. I.

MARX, Karl. Manuscritos econômico-filosóficos e outros textos escolhidos. 4. ed. São Paulo: Nova Cultural, 1987.

MARX, Karl \& ENGELS, Friedrich. A ideologia alemã: I Feuerbach. 4. ed. São Paulo: Hucitec, 1984.

SCHAFF, Adam. Linguagem e conhecimento. Coimbra: Livraria Almedina, 1974.

VÁZQUEZ, Adolfo Sánchez. Filosofia da práxis. 2. ed. Rio de Janeiro: Paz e Terra, 1977. 